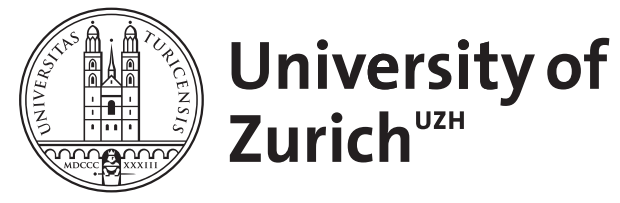

\title{
Area formation in morphosyntax
}

\author{
Glaser, Elvira
}

DOI: https://doi.org/10.1515/9783110312027.195

Posted at the Zurich Open Repository and Archive, University of Zurich

ZORA URL: https://doi.org/10.5167/uzh-85853

Book Section

Published Version

Originally published at:

Glaser, Elvira (2013). Area formation in morphosyntax. In: Auer, Peter; Hilpert, Martin; Stukenbrock, Anja; Szmrezcsanyi, Benedikt. Space in language and linguistics : geographical, interactional and cognitive perspectives. Berlin: De Gruyter, 195-221.

DOI: https://doi.org/10.1515/9783110312027.195 


\section{Area formation in morphosyntax}

\section{Introduction}

In the following contribution, I proceed from the fact that the spatial distribution of linguistic phenomena in general as well as in dialectology is not yet fully understood. Spatial distributions are, however, a fundamental characteristic of language, and they play an important role in recent typological discussions. Up until now, reasoning about linguistic borders and about the diffusion of variants was primarily based on phonological data. The role and behavior of syntactic variation (in a wide sense, including morphosyntax) ${ }^{1}$ were nearly completely outside the mainstream. Before dealing with specific problems in (morpho)syntax-centered dialectology (Section 3), I will therefore review the literature on variant distributions (Section 2). Section 4 is concerned with modern dialectological research avenues, and Section 5 discusses basic questions in dialect geography, as well as in contact linguistics and typology. Section 6 concludes and re-emphasizes the fundamental issue of feature distributions as a common challenge in geolinguistics.

2. The geographic distribution of linguistic features: General considerations

\subsection{Terminological clarification}

The quest for linguistic differences between neighboring communities has informed dialectological scholarship since its inception. Nerbonne and Heeringa maintain that it is "axiomatic in dialectology that language variety is structured geographically" (2007: 287). In this contribution, I take the undisputable spatial distribution of linguistic features as my starting point. By "spatial distribution" I refer to the fact that linguistic features are neither evenly nor randomly distributed in a speech community or within closely re-

1 In this contribution syntax is referred to in a rather wide, pre-theoretical sense so as not to exclude interesting grammatical phenomena. This does not mean that the analyst cannot subsequently draw on narrower definitions of morphology and syntax if different spatial distributions are suspected. 
lated neighboring varieties; instead, they are clustered in certain regions and absent in others. Of course, this does not mean that all linguistic variables show this behavior. There are, however, linguistic features that exhibit an uneven distribution within a given area, a fact that oftentimes puts the native speaker in a position to locate other speakers - an outgrowth of the spatial indexicality (Oesterreicher 2007: 62) of language. In what follows, the notions space and spatial refer to a physical extension in general, i.e. to a confined area where speakers live and use common linguistic features. With respect to a concrete geographical extension, the more or less interchangeable notions area and region are preferred. "Region", however, is reserved for reference to traditional geographical spaces or in order to differentiate between local places and larger, supra-local regions. So, area is the most neutral expression in this context. ${ }^{2}$ The differentiation of place versus space in a more social or geographical sense will not concern us in this paper.

\subsection{Linguistic boundaries in various linguistic approaches}

The relevant theories about the spatial character of dialects largely date back to the early $20^{\text {th }}$ century. Dialect borders were no longer seen as reflecting the settlement borders of old tribal groups. This was a consequence of a change affecting the status of tribes. They were no longer considered fixed entities but had changed into historically and culturally shaped subjects without precise inherited settlement places. The historical and cultural context was seen as determining the position of isoglosses, because often isoglosses were found overlapping with historical boundaries or other aspects of local culture. Thus, it seemed obvious that there must be a correlation between these phenomena, although to this day the exact nature of this correlation is not clear. Despite much criticism of the Kulturraum-paradigm developed by the German kulturmorphologische Schule (cf. Knobloch 2010: 108, 122), the idea that ancient communicative boundaries are mirrored in dialect boundaries survives in modern sociolinguistic research (Britain 2010: 154). After the rejection of $19^{\text {th }}$ century determinism about the influence of geographical features on language, physical boundaries are nowadays widely seen as less important. As only one factor impeding communication among many, their effect can at most be considered an indirect one. Auer (2005) has argued that "imagined" borders, as cognitive constructs, may sometimes explain lin-

2 In German, the term Raum, which is widely used in this context, translates into both area and space. For a critical discussion of the linguistic concept of Raum and its - sometimes problematic - implications see Oesterreicher 2007. 
guistic areality better than "real" communicative barriers. In modernity (where real, physical or political, barriers are rare) in particular, the concept of communicative boundaries seems to be more convincing than the traditional one. We are still left, however, with the problem of how to explain the genesis of the imagined borders. A similar issue is discussed in Britain (2010), according to whom dialect boundaries are "often found in breaks between the socio-spatial networks" (2010: 151).

A completely different approach to explaining the location of dialect boundaries is Moulton's (1961) structuralistic attempt to define limits of variation. Labov (2006: 4) cites Moulton's work as a rare example of work in dialect geography that is relevant to general linguistics. According to Moulton, the diffusion of certain dialect features in a given area can be explained by investigating pre-existing language systems. Thus, the split of back vowels in certain Swiss German dialects is explained as being conditioned by a certain type of front vowel system. Though Moulton's attempt was much admired and often cited, ${ }^{3}$ it did not attract a lot of subsequent work. There are, however, more recent models of language change (cf. Haas 2010) that are broadly in line with Moulton's idea that there are language-internal motivations for isoglosses. Schmidt (2010), for example, has presented a linguistic dynamics approach that incorporates Moulton's view of dialect atlases as linguistic laboratories. The comparison of $19^{\text {th }}$ century atlas data to recent investigations makes possible a real-time analysis of changes in the spatial limitation of linguistic features, and thus enables an assessment of the role of internal and external factors for the construction of dialect boundaries. This is compatible with Heap's stance (Heap 2006: 615) that "a measure of preexisting linguistic similarity" between neighboring varieties should be included in geolinguistic models. Oesterreicher's (2001) concept of "Übernahmebereitschaft" ('borrowing readiness') works along similar lines, and addresses the fact that many sociolinguistic models of feature diffusion are focused too narrowly, according to Oesterreicher, on external features.

In historical linguistics, too, isoglosses matter. Consider a recent workshop that raised the question whether "related isoglosses spread with similar speed and/or steepness. "' Whatever "related" exactly means, this formulation insinuates that there is a deeper linguistic connection between the isoglosses

3 See the discussion in Gilles and Siebenhaar 2010: 772-773.

4 International Conference of Historical Linguistics, convenors: Roeland van Hout (Nijmegen), Gertjan Postma (Meertens Instituut), Giuseppe Longobardi (Trieste). 
of different features. Proposals to include the factor "space" in quantitative models of language variation likewise attest to a broad consensus in the community that "space" is important.

\subsection{Diffusion of innovations in various approaches}

Obviously, a research question closely connected to the explanation of dialect boundaries is how to model the spread of linguistic innovations. Innovation diffusion has indeed been a major subject during the last 50 years of sociolinguistic scholarship. In early American and British variationism, the spatial aspect of diffusion was more or less ignored, while the social embedding of new variants at individual locations was in the focus of sociolinguistic interest. Later on, with the development of various models of diffusion such as wave diffusion, cascade diffusion, or cultural hearth diffusion ${ }^{5}$, space reentered the variationist sociolinguistics paradigm - in particular in the form of distance measures, along with gravity models, adopted from economic geography. The basic idea behind all these models is that linguistic innovations spread thanks to varietal contact, just as other behavioral innovations are transmitted thanks to social contact. The models differ in the conception of the hierarchies of the varieties in contact which the features follow during their diffusion. The cascade model, for example, attributes more importance to larger population centers. In the end, however, diffusion models suggest that we should be dealing with a more or less homogeneous distribution of the new feature within a larger area.

Extant work on the diffusion of variation has several shortcomings. For one thing, while previous studies may explain the general process of innovation diffusion, they fail to shed light on the related problem of dialect boundaries as discussed above. ${ }^{6}$ And even the basic idea of innovation diffusion by contact faces a paradox of sorts: it is commonly assumed that neighboring speakers tend to accommodate. Accordingly, neighboring dialects are usually more similar than distant ones, and they should converge over time. Yet, as Chambers and Trudgill (1998: 93) state, patterns of "criss-crossing isoglosses separating even contiguous villages from one another" are characteristic of regions with "a long settlement history". When the settlement history does not go far back in time, "dialect features tend to be shared over relatively great distances". Obviously, there are two forces at work. One is

5 For a short description of the different models, see Britain 2010: 148-151.

6 For a discussion of critical points based on Gregory 1985, see Britain 2009: 149-151. 
the tendency towards accommodation in discourse. The other force derives from the fact that language is always subject to change; as a consequence, the propagation of the changed features creates new differences between neighboring speech communities.

Dialectometry is one of the geolinguistic disciplines that investigate the link between geography and linguistic features. Recent research indicates that the neighborhood effect was perhaps overestimated; cf. Nerbonne and Heeringa's statement "[W]e interprete the role of geographic proximity and increased social contact not as forces promoting linguistic similarity but rather as forces promoting linguistic differentiation" (2007: 293). Nonetheless, based on the investigation of a great number of dialect variants Nerbonne and Heeringa judge the influence of geography as massive (2007: 274), and they offer that "the strength we have shown geography to have as an explanatory variable makes it nearly inconceivable that social variables [...] could ever be stronger" (291). Nerbonne (this volume) discusses various concepts of geography, some relating to different operationalizations of distance (physical, linear; or logarithmic distance; travel distance; and so on), and one relating to locations' affiliations with dialect regions. On the basis of German dialect data Nerbonne shows that distance as well as dialect area membership can account for pronunciation differences to a certain degree. The two notions in conjunction account for about $47 \%$ of the total variation. In any case, the results of the study support the concept of areal clustering rather than that of a dialect continuum. Note that Nerbonne conceives of dialect regions as a kind of social network, a concept that could explain their influence.

The Augsburg-Ulm dialectometry project (Rumpf et al. 2010) has yet another focus: analyzing the distribution of individual linguistic variants in order to provide "insight into factors that determine these distributions" (2010: 74). Based on lexical data from the Sprachatlas von Bayerisch-Schwaben (1996-2009), the project seeks to test the hypothesis "that linguistic similarity entails similar spatial structures" (2010: 75). First results reveal a certain role of close semantic relationships in shaping similar spatial distributions (2010: 92). Future research must quantify the extent to which language-external or language-internal factors contribute to spatial structures; at present the Augsburg-Ulm dialectometry project refrains from giving far-reaching explanations of how the structures could have evolved.

Schmidt's (2010) dialectology approach relies on the concept of linguistic synchronization - a kind of calibration of the language competence of individuals through linguistic interaction. In his view, it is not only external factors that determine the ultimate propagation of linguistic features. Rather, there 
are also cases of clear interaction of internal factors limiting the spread of features. This is quite in line with Haas (2010), who sketches a model of dialect geography originally developed in the 1970s and updated since against the backdrop of the recent (sociolinguistic) models of feature diffusion. Taking the example of short vowel lowering and long vowel raising in Swiss German dialects, Haas presents a sophisticated diffusion model which distinguishes between extensive diffusion of a new feature (relative to speaker and space) and intensive diffusion (relative to the language system) (2010: 657) within a linguistic continuum. According to Haas, the different dialect areas reflect different stages in the diffusion process, which exhibits a certain "internal and implicative coherence" (2010: 653). The role of phonemic systems functioning "as supportive, impeding, or formative factors" (Haas 2010: $657)$ in the adoption of the innovations can be studied on dialect maps. Thus, Haas (2010) argues for language-internal constraints on the diffusion process. He points out that "the linguistic coherence of a region is more important than its boundary" (2010: 664).

\subsection{Interim summary: Spatial distributions and related questions}

In summarizing the different approaches to the explanation of spatial distributions, we note that there are three factors that are recurrent in the literature: (1) settlement histories, (2) internal (i.e. structural) factors, and (3) patterns of communication. ${ }^{7}$ Labov (2006: 9) defines three corresponding questions, dubbing them "the broader questions of causation that are specific to dialect geography" and subsequently considers the role of these factors concerning the expansion and location of dialect boundaries. On the basis of the Atlas of North American English (ANAE), Labov shows that there are correspondences in the location of different phonological isoglosses when they are structurally related (Labov 2006: 305). He also concedes, however, that the structural considerations "do not fully explain why the North/Midland boundary remains so firmly in place" (Labov 2006: 305), and calls for "further explorations into the communicative patterns and cultural geography of the area" (Labov 2006: 305). Whereas settlement history is no longer considered important in recent research, it is the exact role of communication networks that is in the focus of attention.

A further research question, which is closely related to the issue of feature diffusion and language boundaries, concerns the grouping of local dialects

7 Siebenhaar 2010 mentions frequency as an additional factor but considers external factors the most important ones. 
into dialect regions. Nevertheless, it is important to point out that the problems are not identical. The determination of dialect regions is typically connected to the quest for isogloss bundles. It is, however, often difficult to obtain clear cut boundaries with nicely coinciding isoglosses. This is why some researchers became convinced that the notion of dialect areas has to be given up in favor of the concept of dialect continua (vgl. Bloomfield 1984 [1933]: 341). When dealing with variation, it is also possible to define boundaries within a continuum quantitatively, as demonstrated by Horvath and Horvath (2001) on the basis of phonological data. With Haas I consider regions "the outcome of diffusion" (2010: 664). Therefore, the issue of dialect groupings is a problem that is subordinate to the quest for general principles underlying the geographic diffusion of linguistic features. Dialect regions, which are never homogeneous, are defined both by speakers and linguists on the basis of certain features, and it is of course interesting to study the extent to which the two concepts of regions, those defined by speakers themselves and those defined by linguists, overlap. However, while it is clear that dialect groupings constitute a major topic both in traditional dialectology and in modern dialectometry (see Heeringa and Nerbonne 2001; Kelle 2001), a more detailed discussion of these concepts is beyond the scope of the present contribution. $^{8}$

\section{Dialect geography and morphosyntax: The research questions}

We conclude that there are still plenty of open questions concerning the spread of dialectal features, the location of isoglosses, and the identification of dialect areas. In the past, both dialect-geographical and sociolinguistic-variationist research has been primarily concerned with phonology and sometimes - the lexicon. Grammatical variation has rarely been investigated. With regard to German dialects some scholars have maintained that syntax does not show geographical variation at all. According to Löffler (2003), for example, syntactic variation across dialects is to be explained by principles of oral language production and does not differ from the syntax of the standard language $(2003: 109,116) .^{9}$ Nonetheless, most dialectologists have come to agree that syntactic variants, too, can show a non-random areal distribution.

8 Questions of feature diffusion and its motivations are also discussed with respect to the related issue of dialect convergence (cf. Siebenhaar 2010), another concept that cannot be dealt with here in any depth.

9 B. Szmrecsanyi pointed out to me that in English linguistics similar opinions are to be found, cf. Lass 2004: 374: "English regional phonology and lexis [...] are generally more salient and defining than regional morphosyntax." 
Although dialects do exhibit features of spoken language (such as repetition, ellipsis, or incoherence) it is also true that there are systematic differences in the syntax of various (spoken) dialects. ${ }^{10}$ We find robust evidence for this assumption in different language groups, but suffice it to mention here recent results concerning Dutch and German dialects, especially Swiss German (Barbiers et al. 2005, 2008; De Vogelaer and Devos 2008; Seiler 2004; Glaser 2003; Fleischer 2011). Even in nonstandard language, which is commonly considered to be less structured geographically, we do find variants with a clear difference in their spatial scope. This is true, for example, with respect to the use of the definite article with proper nouns in German. ${ }^{11}$ As far as Swiss German dialects are concerned, the different preferences in the serialization of auxiliary and past participle in present perfect formation were already noticed by the authors of the Swiss German dialect atlas (SDS). A pertinent map showing the ordering of the auxiliary $b i$ ' $\mathrm{I}$ am' and the past participle gsi 'been' in a subordinate clause was consequently included in the atlas (Hotzenköcherle et al. 1975, 261; see Map 1). An area with a nearly exclusive use of the ordering of bi gsi is clearly discernable in the southwest of German-speaking Switzerland.

In addition to word order in the verbal group, investigations carried out in Zurich have identified various morphosyntactic variants that show a spatial distribution in the Swiss German area. These cover various grammatical domains, such as - for example - clause linkage with infinitival purposive clauses as in (1), congruency in passive and resultative constructions as in (2), declension of proper names as in (3), prepositional dative marking as in (4), verb doubling as in (5), depictive marking as in (6), and converb marking as in (7). ${ }^{12}$

10 See the discussion in Krefeld 2008 concerning different sources of linguistic variation which should ideally all be taken in consideration, at least when a dialect location is taken as a starting point.

11 Map 76 in Eichhoff 2000: 76 depicts the results of a survey investigating the use of a definite article along with the female proper name Ruth. Although one might have the impression that the use of the definite article with proper names is quite widespread, it is actually only in the southern part of the German-speaking area that the article is omnipresent.

12 For maps and details concerning (i) purposive clauses see Seiler 2005, (ii) verb doubling: Frey and Glaser 2007, (iii) resultative and depictive marking as well as the declension of proper names: Bucheli Berger 2005, 2006, Bucheli Berger and Glaser 2004, (iii) differential object marking concerning dative case: Seiler 2003. For general information on the SADS project see http://www.ds.uzh.ch/dialektsyntax/ phaenomene.html. 


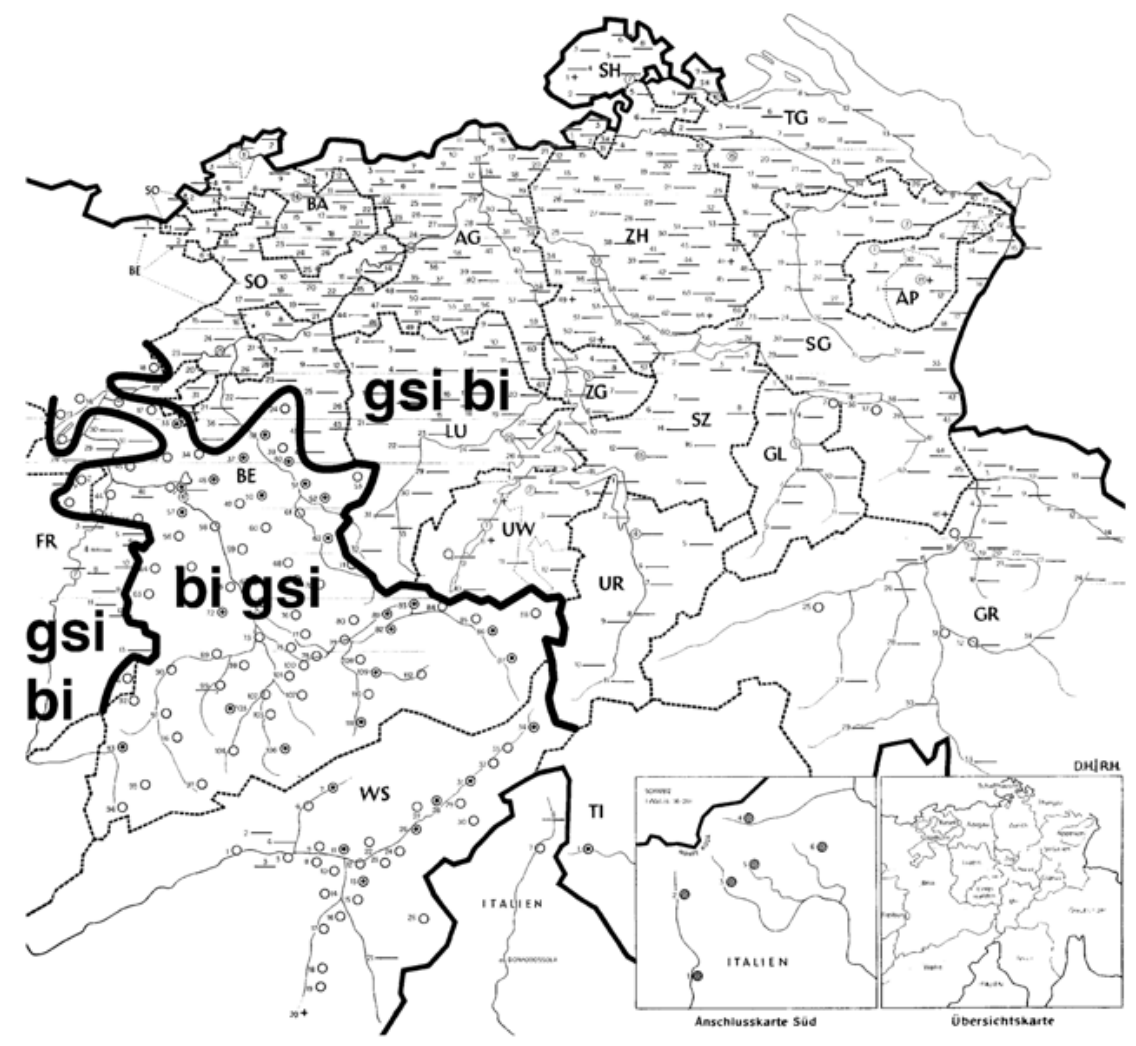

Map 1. Word order variation in Swiss German (cf. Hotzenköcherle et al. 1975, map 261)

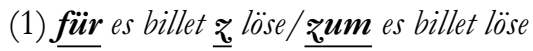
'in order to buy a ticket'

(2) d-strooss is immer no ufgrissni/ufgrisse 'the street is still torn up'

(3) $i$ ha (de) Fritz( $($ en $)$ gseh

'I have seen Fritz'

(4) daas ghöort (i/a) miinere Schweschter 'this belongs to my sister' 
(5) er laat de Schriiner (la) cho

'he has the carpenter come'

(6) si trinkt d-Milch warm(e)

'she drinks the milk hot'

(7) er isch binketse heigloffe

'he went home limping'

We notice quite different geographical patterns in the distribution of the above variants. Whereas resultative marking, as in (2), exhibits a south-north split well-known in Swiss German dialectology for phonology and the lexicon, ${ }^{13}$ there are also several small-sized areas such as those exhibiting depictive marking (Map 2) and converb marking (Map 3). The west-east division known from other linguistic levels is also to be found, e.g. with respect to the construction of the infinitival purposive clause and verb doubling. There are, moreover, phenomena, such as for instance prepositional dative marking, whose regional distribution does not seem familiar (cf. Seiler 2003). One may conclude from this that the distribution of morphosyntactic variants is quite inconspicuous in comparison with other linguistic levels.

That geographically conditioned syntactic variation indisputably exists does not entail, however, that the distribution of syntactic variants is identical to the distribution of phonological or lexical variants. It seems, for example, quite common that a syntactic variant is restricted to a specific area, but nevertheless competes with another more widely used variant, as is the case with depictive marking in Swiss German (see above). As a tendency, this situation seems to be more common in syntax than in phonology - but as yet we do not know enough about the specifics of dialect grammars to conclusively judge the case. Be that as it may, the fundamental questions in dialect syntax are the classical ones well-known from the study of dialect phonology or lexis:

- What is the distribution of the variants, and how can it be described? Are there specific geographical patterns?

- Are we dealing with a continuum, or do we find clear-cut boundaries?

- How can we explain the distribution of the variants, and the location of the isoglosses?

13 The southern part is more or less the alpine region known as Höchstalemannisch ('highest Alemannic') in traditional dialectological terms. 


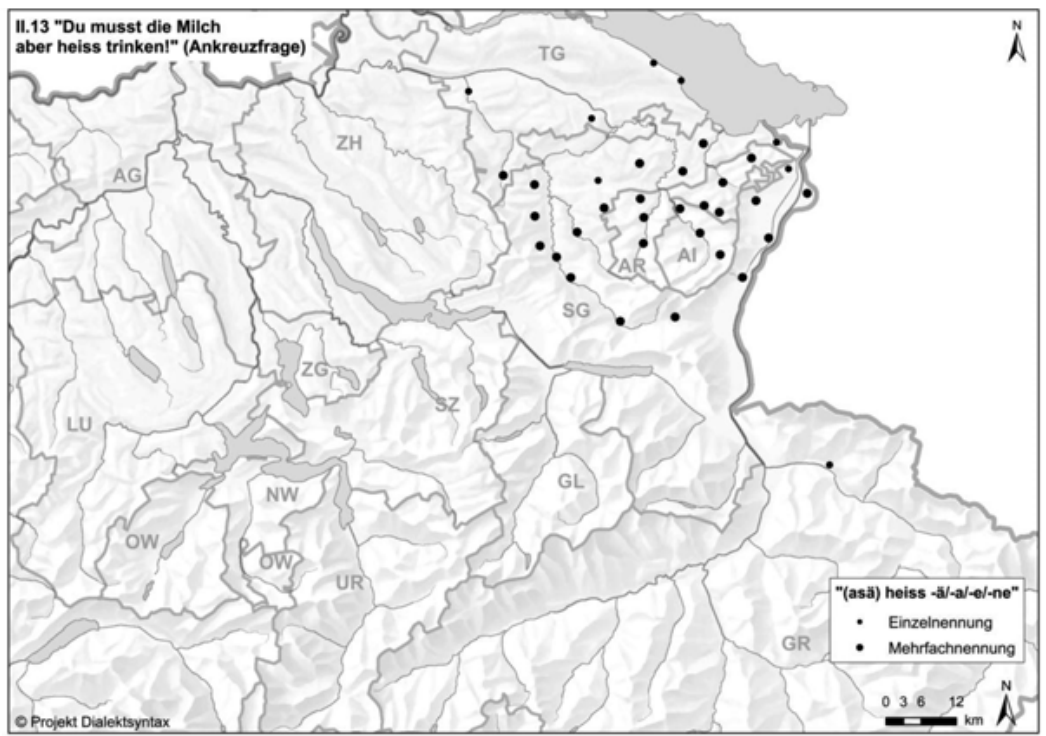

Map 2. Depictive marking in north-east Swiss German (SADS data, multiple choice question II.13)

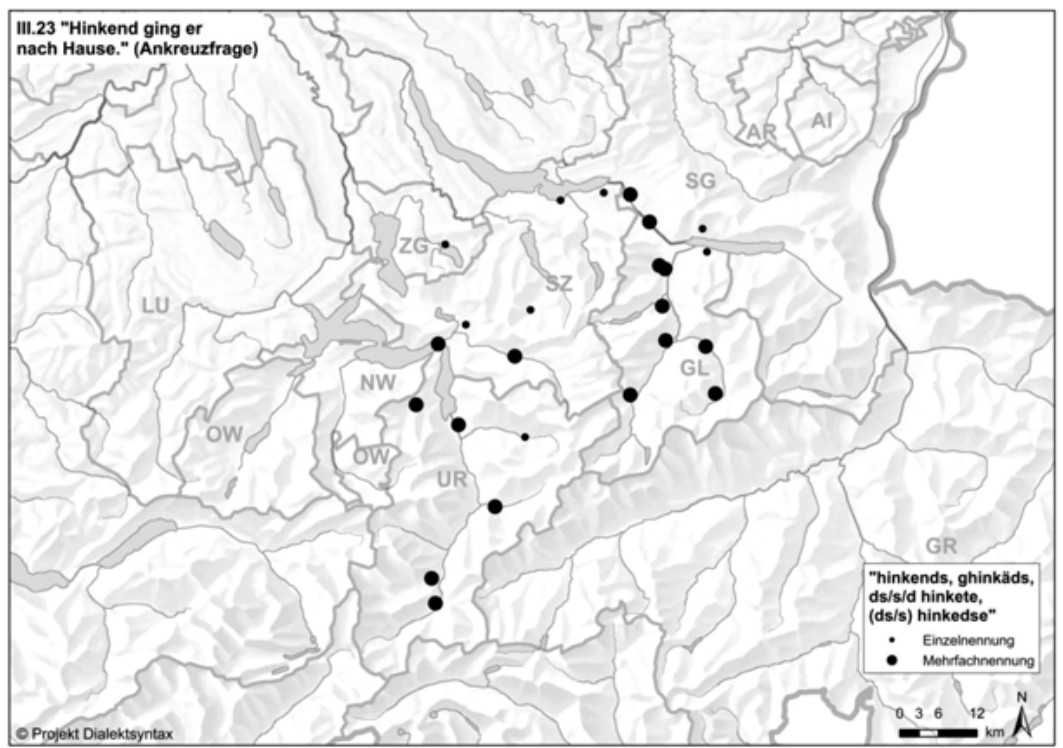

Map 3. Converb marking in central Swiss German

(SADS data, multiple choice question II.23) 
An additional question that is specific to the study of dialect syntax is the following:

- Is there a basic difference between syntactically defined areas and areas defined by other linguistic levels?

Indeed, area formation in syntax begs some fundamental questions concerning the nature of grammar. The status of syntactic variants differs across different theoretical frameworks: syntactic variation is either seen - for example, in formal syntax - as deeply rooted in grammar and linked to other (grammatical) phenomena, or else it is considered the outcome of more or less deliberate speakers' choices, as in sociolinguistics. In the face of these differing theoretical views, the distribution of syntactic variants in space is certainly a major topic thanks to competing explanations as to how the distributions come about. And so it is worthwhile to take a closer empirical look at the spatial variation of (morpho-)syntactic phenomena.

We note in this connection that in the past few decades, theoretical linguists have become interested in dialectal variation. In the Generative Grammar framework, dialect variants are considered to be indicative of microvariation, i.e. minimal differences between language systems, and as such they are of interest when investigating "Universal Grammar" (cf. Weiss and Brandner 2009). Minimal differences in grammar can help to uncover the boundaries of variation. As a consequence, it is now no longer exclusively the grammatical system of the individual speaker that is in the theoretical focus, but also geographically conditioned variation. The distribution of the features in space is not believed to be arbitrary, at least as long as it shows clear patterns. The authors of the manual of the Dutch Dialect Syntax Project put it as follows: "If two maps depicting distinct morpho-syntactic variables show a considerable overlap, one might want to see if these phenomena are correlated in a meaningful way." ${ }^{14}$ It is the explanation of these correlations which is considered of theoretical interest, quite similar to Moulton's phonological program or Haas' model of sound change (see above). So far, attempts to model morphosyntactic diffusion in space have been quite rare. Barbiers (2009), after having discussed the empirical evidence in several cases of Dutch dialect variation, concludes "that the syntactic module allows for some optionality" (2009: 1621), but there are limits to syntactic variation. These limits are seen in general syntactic conditions. Barbiers claims, for example, "that the base structures of the language varieties under discussion do not vary" (Barbiers 2009: 1621). In the context of the underlying idea of a common gram-

14 See the manual of the Dutch Dialect Syntax Project: http://www.dialectsyntax.org/index.php/manual-mainmenu-67/introduction-mainmenu-70. 
mar, the question is why some dialects make some choice while others make another one. These choices could be due to sociolinguistic circumstances, but it is of course also possible "that the grammatical properties determining such choices have not been discovered yet" (Barbiers 2009: 1622). This last point, according to Barbiers, is the reason why more data on dialectal syntactic variation are needed. Though I agree that we need more data, the notion of a common grammar underpinning dialects is somewhat unpalatable from a dialectological point of view. In sum, then, as far as I can see some mere first steps have been made to devise a theory of how geographical patterns of grammatical features come about. For example, exploring correlations between various linguistic levels with respect to distance Spruit et al. (2009: 1640) concede "that extralinguistic, but clearly non-geographic explanations are equally plausible as candidates to explain the correlation".

As mentioned in the previous section, in historical linguistics spatial distributions have always been considered an important source for the reconstruction of language change, as synchronic diversity can be interpreted diachronically. Yet, in this connection the status of syntax is unclear. Longobardi and Guardiano (2009) marshal a quantitative analysis using the parametric comparison method on the basis of 15 standard languages, and offer "that syntactic differentiation proceeds more slowly than lexical differentiation" (2009: 1694) - a conclusion which is not uncontroversial and stands in contradiction to classical comparative principles which for reconstruction hardly ever take syntax into consideration.

Our literature review would seem to have suggested that at present there is no agreed framework for analyzing the geographical distribution of grammatical features and constructions.

\section{Dialect geography and morphosyntax: Some research pathways}

The fact of the matter is, then, that there seems to be a renewed interest in the description and explanation of geographically conditioned linguistic variation, which for a long time has been of marginal interest in general linguistics. There are recent handbooks and new periodicals that deal with the topic ${ }^{15}$, a growing number of dialect atlases introducing new methods or subjects, ${ }^{16}$ and - in particular - there is the prospering field of dialectometry.

15 Suffice it to mention the recently published first volume of Language and Space (Auer and Schmidt 2010) and the periodical Dialectologia et Geolinguistica founded in 1993.

16 Let us mention here Labov et al. 2006 based on telephone interviews in North America and Barbiers et al. (SAND 2005; 2008) for Dutch dialect syntax. 
Dialectometry essentially counts linguistic differences between locations in a dialect grid (cf. Goebl 2010 for an overview). The calculation of dialect differences can be visually depicted in colorful maps, usually based on aggregate measures of linguistic distance (or similarity). In this fashion more general spatial patterns can be identified, which can then be explained intra-linguistically or extra-linguistically. This classic form of dialectometry has quite rarely been used in German dialectology, and dialectometric work on aggregate morphosyntactic variability is non-existent. In any event, dialectometricians may also correlate linguistic distances with geographic distances (or other distance measures), which approximate the likelihood of contact and communication. Interestingly, previous research in this spirit has identified quite different correlation strengths. Exploring correlations between linguistic levels and geography, Spruit (2008) found, among other things, a correlation value of 0.55 between syntactic distances and geographic distances, based on Dutch dialect atlas data (Barbiers et al. 2005). This means that only about $30 \%$ of the differences can be accounted for by geographic distances. On the basis of a reduced data set of Dutch dialects, however, Spruit et al. (2009) report a stronger correlation, such that $45 \%$ of the variation is explained. They consider geography a valuable predictor of linguistic distances. On the other hand, drawing on English corpus data, Szmrecsanyi (2012) reports that less than $10 \%$ of the syntactic variation can be explained by geographic distances, and so he concludes that geography plays a weaker role then one might think. A similarly weak role of geography one would also expect in the case of Swiss German syntax - Zurich-based research indicates that there are many more or less homogeneous syntactic areas, and few phenomena that are distributed in a continuum-like fashion. This is why a simple correlation with geographic distance would actually contradict the impression of a geographically unbalanced distribution of the variants. This impression is rather compatible with Szmrecsanyi's finding that factoring in dialect groupings explains one third of the linguistic variability, which is more than mere geographical distance can account for. Indeed, geography would be "overrated" (Szmrecsanyi 2012) if one would seek to explain syntactic variation mainly by geographical distance.

Szmrecsanyi (2012) also submits that atlas-based dialectometry may exaggerate the role of geography. Now, it is true that dialect atlases focus on features that seem geographically interesting and leave out variation found all over the place. This procedure follows from general cartographic principles. As a matter of fact, an unbalanced geographical distribution is the raison d'etre for a map. An atlas is not intended to present all the relevant data of a local dialect. Mapping requires some degree of significant geographic distribu- 
tion, and this does not exclude the existence of other types of linguistic variation. Certainly, a syntactic peculiarity of low frequency will find its way into an atlas, but it is probably not present in corpus data and does not play an important role in every-day communication. Nevertheless and all the more, its specific geographical range should be subject to dialectological analysis. Whether or not to ignore it in a big-picture analysis of variation depends on what we are interested in. A low-frequency variant can be of structural interest $^{17}$, and it may be considered characteristic by locals and their neighbors. In any case, even if we concentrate on features with a significant geographic distribution, we cannot expect to find a simple correlation between geographic distance and syntactic distance as long as there is a certain amount of features clustering in an area.

Let us put the problem the other way round. It is because geolinguistic variation is neither random nor a mere correlate of geographic distance that it is worth being investigated. The relevant diagram in Spruit (2008: 55) shows that neighboring (Dutch) dialects can be linguistically similar or not, whereas dialects far away from each other are in all likelihood less similar. Within this range (proximity vs. distance), we find various ways in which syntactic variants are geographically distributed. It is the study of these different geographic patterns that will advance our knowledge of the general principles underlying the geographic distribution of linguistic variation. Rumpf et al. (2010) define and analyze clusters of visually similar maps in order to find structural similarities concerning, for instance, semantic relationships. The atlas data they use does not cover morphosyntactic phenomena, yet the methodology presented is suitable for various research questions. Clusters of maps with similar spatial structures may be analyzed with respect to similarities of the grammatical features involved. Thus, research in dialect grammar requires not only a quantity-based comparison of the geographic patterns, but also a qualitative type of areal syntactic comparison. In this perspective, it is crucial to know not only about quantitative similarity but also about cooccurrence patterns, an issue that dialectometrical research has only recently begun to investigate (Spruit 2008: ch. 5). An ambitious objective like this brings about the problem of the classification and assessment of the syntactic variants as the basis for the calculation. Spruit (2008: ch. 5) presents a first sketch of how to manage the measuring of differences in word form and word order.

17 This holds true, for instance, for depictive marking in the North-East of Switzerland; see Bucheli Berger and Glaser 2004. 
Against this backdrop, work is underway in Zurich to explore new dialectsyntactic datasets, for the sake of addressing gaps in our knowledge about dialect syntax. Concerning Swiss German we can rely on data collected from 2000 through 2004 and stored in a database ${ }^{18}$ (cf. http://www.ds.uzh.ch/dialektsyntax/). Preliminary analyses have revealed many morphosyntactic variants which were mapped with the help of GIS software. The mapping technique we have used so far is the one customary in German dialect geography: symbol maps, which plot symbols for different variants at the points of investigation. Such interpretive maps enable the perception of areas where a certain variant occurs, thus giving a visual impression of the linguistic diversity in space. They are similar to maps explicitly presenting areas marked off by lines (isoglosses), but they avoid the lines' often criticized arbitrary character. Visually depicting the distribution of variants in map space is not, however, a straightforward task. It is especially the co-occurrence of several variants at a measuring point - for example, in transition zones - which creates problems. Dialectometrically generated maps draw on color coding, which helps to display the varying pervasiveness of a variant. This sort of information is difficult to integrate in symbol maps. On the contrary, the existence of a specific repertoire of variants at a certain location or in a small area is not substantially more recognizable on a colored map (compare Map 4, which plots symbols, to the choropleth Map 5, based on kernel density estimation (KDE) of dominant variants, both on purposive clause linkage). As a consequence, if we are interested in the actual co-occurrence of variants at a certain location, blended color maps as in Map 5 are per se not helpful. The color maps showing the distribution of a single variant are, however, very useful in order to obtain an impression of an east-west continuum, respectively (see Map 6 and Map 7, taken from Sibler [2011, 29], also based on KDE of the dominant variants).

The discussion of the advantages and disadvantages of choropleth maps show that we need to go beyond customary dialect cartography, with its exact reference to dialect variants and measuring points, to explore new quantitative cartographic methods which are typically based on the aggregation or blending of data. In this context, it is clear that the colored maps used in dialectometry are also subject to interpretation with respect to the spatial distributions mapped. They are particularly apt to provide an overall impression of the similarity of the dialects. But the adequacy of a projection to geography depends on its desired function. We note in particular that the quantitative basis of dialectometrical maps makes possible further numerical

18 For more information see http://www.ds.uzh.ch/dialektsyntax/. 


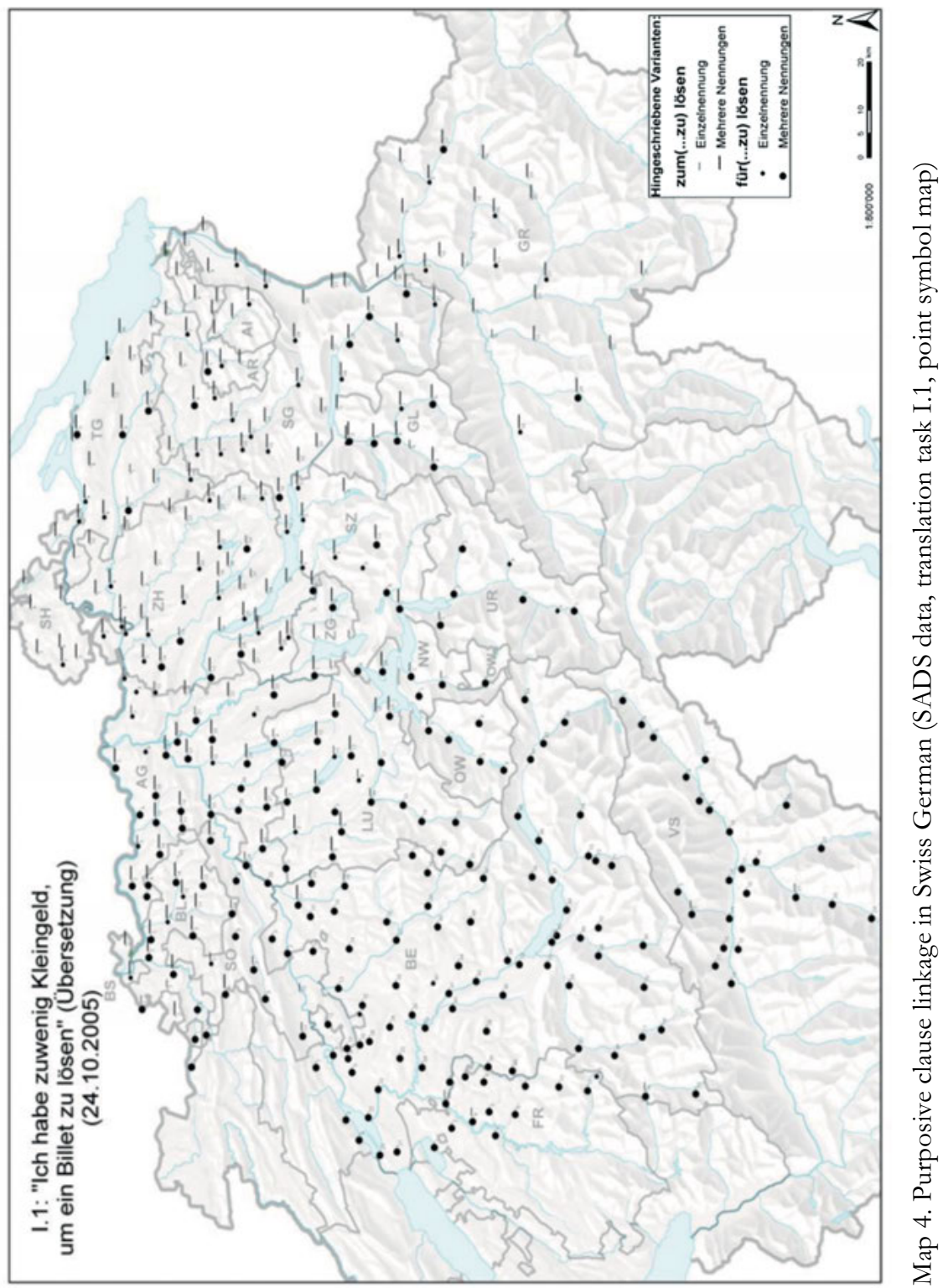




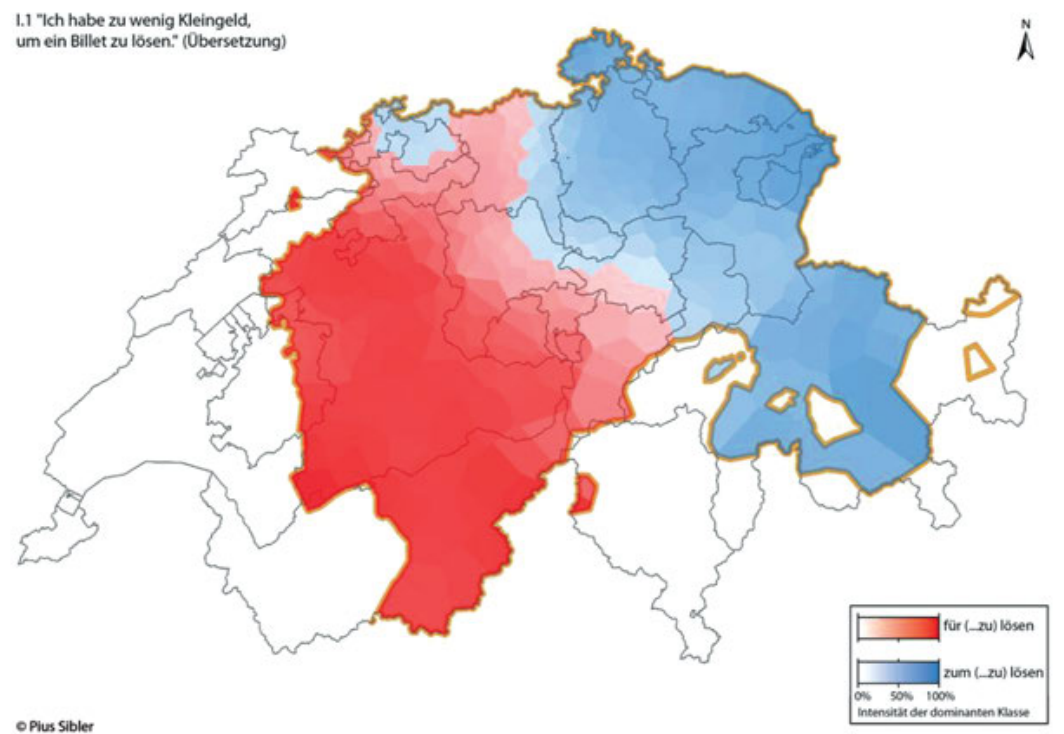

Map 5. Purposive clause linkage in Swiss German (SADS-data, translation task I.1; interpolation based on KDE of dominant variants, see Sibler (2011: 29)

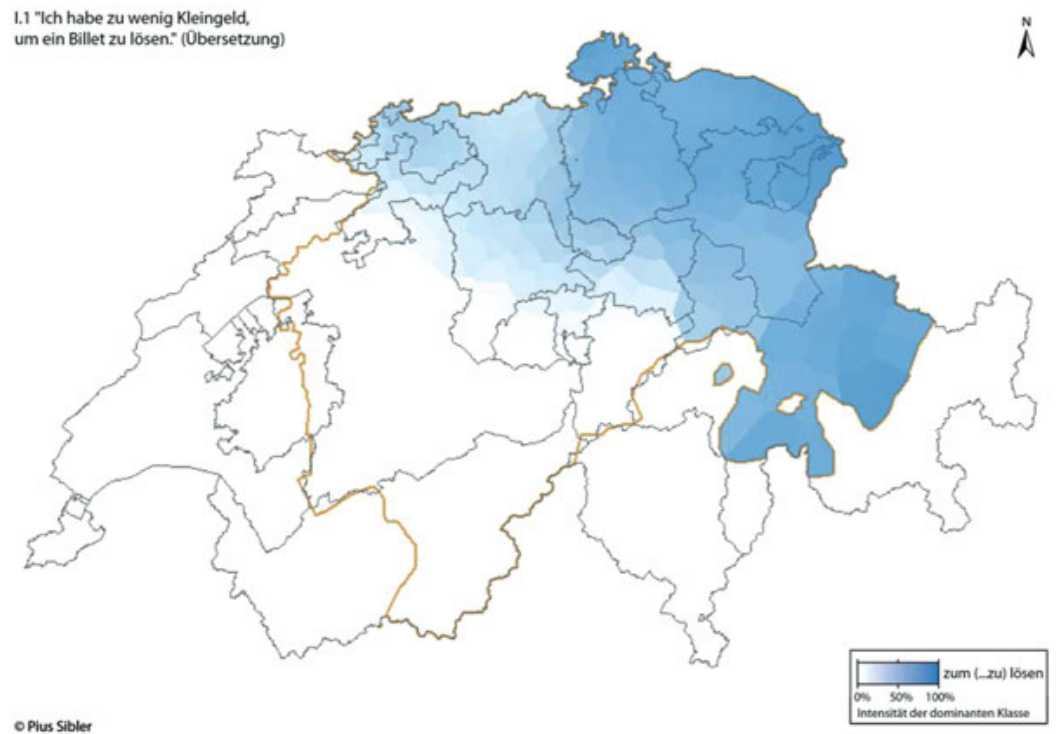

O Pius Sibler

Map 6. Purposive clause linkage in Swiss German (SADS data, translation task I.1; interpolation based on KDE, Sibler 2011: 29): zum-variant 


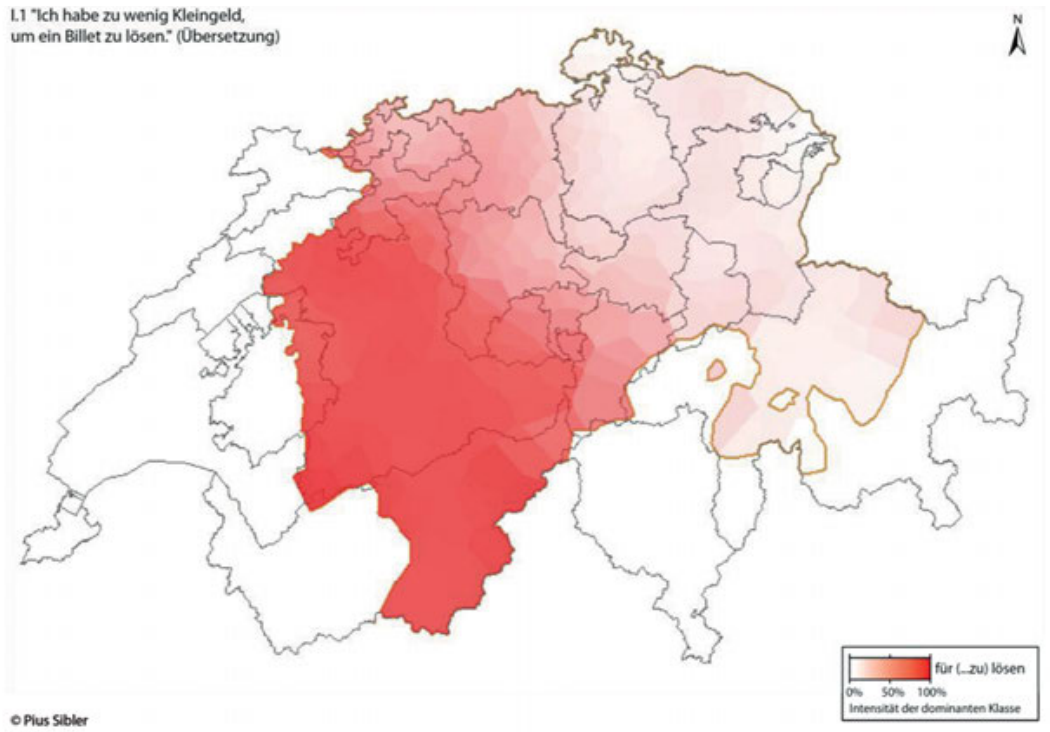

Map 7. Purposive clause linkage in Swiss German (SADS data, translation task I.1; interpolation based on KDE, Sibler 2011: 29): für ... z-variant

approaches to the similarities and dissimilarities underpinning the geographical patterns, as is shown by Rumpf et al. (2010) with respect to lexical maps. Promising research avenues include the simulation of diffusion processes (see Nerbonne 2010), as well as the implementation of topological and cultural information in the modeling.

Dialectologists working in qualitative paradigms have recently started investigating correlations between various syntactic phenomena. Seiler (2005) shows that the spatial co-occurrence of the syntactic variants of infinitival purpose-clause formation in Swiss German dialects (basically e.g. für es billet $\underline{z}$ löse vs. zum es billet löse (in order to buy a ticket') is not random, but rather grammatically organized. He argues for the notion of an inclined plane instead of the classical isogloss. The western variant für z reaches the eastern parts of the Swiss German area, but the further east it goes the more it is restricted in terms of grammatical context and preference. ${ }^{19}$ The same is true, conversely, for the eastern variant zum, which is attested in the most western parts only in a specific grammatical context. Analyzing the three-verb-

19 The questionnaire used in the SADS project asked for an evaluation of the accepted variants as to which one was the preferred one. 
cluster arrangement in Swiss German (e.g. $i$ ban wele gaa 'I have wanted to go'), Seiler (2004) likewise concludes that transition areas are defined not simply by a random mix of two (or more) "consistent" neighboring grammars, but attest grammars of their own. The next step would consist, then, of systematically comparing the areal distribution of the variants and the (non)correspondence of the respective geographic areas in a comprehensive manner. As mentioned above, we already know that grammatical phenomena do not behave in a uniform manner. That means that there will be phenomena with quite clear boundaries and restricted regional occurrence, such as converbs (see above) and other phenomena - for example, the doubled indefinite article in expanded nominal attributes (ä gan₹ ä gueti arbet ('(a) really a good work'), where variation covers a large area (Steiner 2006). The identification of specific geographic patterns begs the question if phenomena showing similar patterns share something in common. Dialectometrical analysis techniques may help us to spot similar patterns, while the analysis and interpretation of communalities is reserved for qualitative dialectological analysis.

Another important research agenda is informed by the following question: "Is syntax different?" 20 Or, in more general terms: "Is there a difference between grammatical areas and areas defined by other linguistic levels?" The crucial issues are co-occurrence patterns and the geographical scope of the variants. As mentioned above, in syntax we often meet the situation that a particular feature characterizes one area, but in a neighboring area we find variation between two features instead - and not another area defined by one typical variant. Isoglosses may thus mark off variation zones and not homogeneous areas. Another hypothesis posits that the range of syntactic features, in general, is larger than that of phonological ones. If this is true, the question arises how we can explain the differential effect of, say, accommodation in phonology and syntax. Discussing the different views on the role of geography, Szmrecsanyi (2012) refers to the assumption "that morphosyntax is less amenable to geographic diffusion than e.g. pronunciational variability." There is indeed a controversy as to the character of syntactic transfer. Whereas some scholars consider syntax to be highly variable, others regard it as rather stable (cf. Spruit 2008: 52). In any case, we know very little about the differential behavior of the various linguistic levels (phonetics, morphology, lexicon and syntax) in geographic space, and specifically we do not currently know whether in fact syntactic constructions vary more freely than e.g. pronunciation features, as is commonly assumed. So, the comparison of syn-

20 This was the title of a talk on Swiss German dialects by Guido Seiler and Claudia Bucheli Berger at the Berkeley Germanic Linguistics Roundtable 2006. 
tactic areas with areas defined by other linguistic levels will help to elucidate the nature of syntactic variation.

Observe moreover that the comparison of historical with modern data may tell us how stable the areal distribution of syntactic variants is, also in comparison to other linguistic levels. The observation of ongoing changes or the discovery of a completed change in the geographical distribution of syntactic variants is informative about the stability of syntactic phenomena. At present we can, for instance, observe how the formation of a recipient passive (the so-called kriegen-passive) infiltrates more and more Swiss German dialects. ${ }^{21}$ In light of the assumption of the specificity of syntactic change, the fact that regional syntactic variants are often not recognized as such even by linguistically sensitive speakers (cf. Spruit 2008: 53) - a finding we have corroborated in our work on Swiss German syntax - is quite interesting. There are, however, important differences across grammatical phenomena. We need further research into possible connections between stability, the salience of morphosyntactic variation, and the exact nature of the grammatical variant (cf. word form, word order, congruency, and so on).

Additionally, we need to know about the extent to which the range of variants and the existence of boundaries are dependent on the design of the inquiry. We need to explore, for example, how areas and boundaries would change if we only took into account one informant per measuring point in accordance with the traditional dialectological criteria. Moreover, we need to specifically study how the number of informants impacts the resulting variability at selected locations, and we should consider scaling effects as a result of basing the analysis on a larger or smaller number of measuring points. This is a topic that would profit from an interdisciplinary approach, as scaling effects are a well-known phenomenon in geographic information science.

\section{Dialect geography and areal typology: Common questions}

The quest for the grammatical conditioning of syntactic variation within dialects is fully in line with the approach outlined in Haspelmath (2008), who calls for fine-grained analyses of hierarchies within restricted grammatical domains of various languages. This line of analysis assumes, however, the existence of linguistically motivated co-occurrence patterns, and of grammatical limits of the transferability of variants from one language system to another. This is not uncontroversial. To some degree, this assumption is incompatible with the notion that variants spread subject to sociolinguistic cir-

21 For more details see Glaser 2005. 
cumstances and stop at real-world or imagined borders. If we accept this notion we have to wonder about the extent to which the co-occurrence of variants is interesting at all to grammatical research. For according to this model co-occurrence patterns would have been created by sociological factors rather than by language-internal factors. Accordingly, typologists are faced with the same puzzle as dialectologists interested in the diffusion of syntactic features. The central dialectological issue of area formation through morphosyntax closely resembles the typological core issue as stated recently in Bickel (2007): "What's where why?" Our concern is to determine if it is possible to base the answer to this question on linguistic facts, or not. The existence of syntactic areas where a certain variable is present prompts various questions with respect to the diffusion of syntactic constructions. The areal clustering of language structures is likely due to contact between speakers. Accordingly, area formation is linked to contact linguistics. Both in language contact and in dialect contact we observe transfer processes of syntactic variants. The transfer of grammar in contact situations has become a major subject in contact linguistics research in the last decennia (cf. Heine and Kuteva 2005; Matras and Sakel 2007). Nevertheless, there is no agreement concerning the linguistic or social conditioning of transfer and the limits of transferability. So, contact linguistics is confronted with the same questions as dialectology as regards the impact of social factors vis-à-vis language-internal constraints guiding the results of language contact.

A comparative approach to contact linguistics combined with cross-linguistic typological work (see Siemund and Kintana 2008) seems to be a promising way to probe the mechanisms of linguistic convergence, which is a fundamental process in the evolution of a linguistic area (Spracbbund). As for areal linguistics, Bickel and Nichols (2006) attempt to redefine linguistic areas in order to solve the notorious problem of nonconformity and fuzzy boundaries, a problem that besets dialectology as well. Thus, cross-disciplinary reflection on questions of area formation, boundary formation, language contact (including dialect contact), feature diffusion and finally the association of language and geography is imperative. Holman et al. (2007) explicitly associate their concept of 'isolation by distance' among the world's languages, which is inspired by population genetics, ${ }^{22}$ with the situation faced by dialectologists. Indeed, their intention to investigate "empirical correlations between linguistic differences and geographical distance" (395) re-

22 Holman et al. 2007: 394 mention spatial autocorrelation as an equivalent term used by ecologists to refer to distribution in geographical space. It is also used in Geographic Information Science; see Sibler 2011: 62, 64. 
sembles very much the dialectological research question addressed in dialectometry. The common goal of dialect geography, dialectometry and areal typology is to better understand the mechanisms behind the geographical distribution of linguistic features. As it is often grammatical phenomena that are in the focus of areal typology, there is substantial potential for cross-fertilization between dialect syntax and areal typology.

\section{Concluding remarks}

Although the quest for the motivations of the distribution of dialectal variants - in other words, the location of isoglosses - is an old one, we still know very little about these issues, at least as far as morphosyntax is concerned. In the end, we aim to come closer to solving the problem of explaining the distribution of variants and the location and nature of syntactic isoglosses. There is a very fundamental question concerning feature diffusion that is still unanswered: Is it really true that linguistic innovations diffuse thanks to (social) contact, just as other behavioral innovations do - or is there a difference? Interdisciplinary approaches are needed to address this question.

Because typologists are likewise interested in finding correlations between linguistic features, the question of how the coexistence of features comes about is highly relevant in typology as well. Pure coincidence cannot be ruled out, but since the distribution of features across language areas is commonly attributed to language contact, there is a link to contact linguistics. In this context, we may wonder about the extent to which the diffusion of variants can be reduced to the effect of social contact, and about the extent to which there are structural limits.

In sum, the question of area formation is, to this day, a central question for the understanding of language and language change. It is in any event not the case that the issue of geographically distributed linguistic phenomena is disappearing in modern times. The idea that dialect areas were stable in the past and are only now becoming fuzzy seems to be a figment of $19^{\text {th }}$ century thinking. It is a natural development in feature diffusion that geographical distributions emerge in real time, as is shown by Labov (2006) concerning $20^{\text {th }}$ century phonological change. Christen (2003), too, points to the areal character of expressive particles which have come up only recently in modern Swiss German youth language. It may be that the size of linguistic areas will change to become larger in the future - but geographical distributions as such are here to stay. As a consequence, they merit the linguist's attention. 


\section{References}

Auer, Peter 2005: The construction of linguistic borders and the linguistic construction of borders. In: Markku Filppula, Juhani Klemola, Marjatta Palander \& Esa Penttila (eds.), Dialects across Borders, 1-30. Amsterdam/Philadelphia: Benjamins.

Auer, Peter \& Jürgen E. Schmidt (eds.) 2010: Language and Space. Berlin/New York: Mouton de Gruyter.

Barbiers, Sjef 2009: Locus and limits of syntactic microvariation. Lingua 119: 1607-1623.

Barbiers, Sjef, Hans Bennis, Gunther De Vogelaer, Magda Devos \& Margreet van der Ham 2005: Syntactic Atlas of Dutch Dialects. Volume I: Pronouns, Agreement, and Dependencies. Amsterdam: Amsterdam University Press.

Barbiers, Sjef, Hans Bennis, Gunther De Vogelaer, Johan van der Auwera \& Margreet van der Ham 2008: Syntactic Atlas of Dutch Dialects. Part II: Auxiliaries, Verb Clusters and Negation. Amsterdam: Amsterdam University Press.

Bickel, Balthasar 2007: Typology in the 21st century: Major current developments. Linguistic Typology 11: 239-251.

Bickel, Balthasar \& Johanna Nichols 2006: Oceania, the Pacific Rim and the theory of linguistic areas. In: Proceedings of the 32nd Annual Meeting of the Berkeley Linguistics Society. Available online at: http://www.uni-leipzig.de/ bickel/research/papers/bickel_nichols_bls32.pdf.

Bloomfield, Leonard 1984 [1933]: Language. Chicago: University of Chicago Press.

Brandner, Ellen \& Helmut Weiss (eds.) 2009: Microvariation in the quantificational domain. Special Issue of Journal of Comparative Germanic Linguistics 12.

Britain, David 2010: The variationist approach. In: Peter Auer \& Jürgen E. Schmidt (eds.), Language and Space, 142-163. Berlin/New York: Mouton de Gruyter.

Bucheli Berger, Claudia 2005: Passiv im Schweizerdeutschen. In: Helen Christen (ed.), Dialekt/ologie an der Jahrtausendwende. Linguistik online 24 (3): 49-77.

Bucheli Berger, Claudia 2006: Syntaktische Raumbilder im Höchstalemannischen. In: Hubert Klausmann (ed.), Raumstrukturen im Alemannischen. Beiträge der 15. Arbeitstagung zur alemannischen Dialektologie, 91-96. Schloss Hofen, Vorarlberg (Schriften der Vorarlberger Landesbibliothek, Band 15). Graz/Feldkirch.

Bucheli Berger, Claudia and Elvira Glaser 2004: Zur Morphologie des (ko)prädikativen Adjektivs und Partizips II im Alemannischen und Bairischen. In: Franz Patocka \& Peter Wiesinger (eds.), Morphologie und Syntax deutscher Dialekte und Historische Dialektologie des Deutschen. Beiträge zum 1. Kongress der Internationalen Gesellschaft für Dialektologie des Deutschen, Marburg/Labn, 5.-8. März 2003, 189-226. Wien: Edition Praesens.

Chambers, Jack K. \& Peter Trudgill 1998: Dialectology (2nd edition). Cambridge: Cambridge University Press.

Christen, Helen 2003: Uu fein, welts guet und rü̈dig schöön. Überlegungen zu lexikalischen Aspekten eines SchweizerDeutsch der Regionen. In: Beat Dittli, Annelies Häcki Buhofer \& Walter Haas (eds.), Gömmer MiGro? Veränderungen und Entwicklungen im beutigen SchweizerDeutschen, 25-38. Freiburg/Schweiz: Universitätsverlag Freiburg.

De Vogelaer, Gunther \& Magda Devos 2008: On geographical adequacy, or: how many types of subject doubling in Dutch. In: Sjef Barbiers, Margreet van der Ham, 
Olaf Koeneman \& Marika Lekakou (eds.), Microvariations in Syntactic Doubling, 249-274. Bingley: Emerald.

Eichhoff, Jürgen 2000: Wortatlas der deutschen Umgangssprachen, Volume 4. München/ Bern: K.G.Saur.

Fleischer, Jürg 2011: ... und habe es ihr gesagt: Zur dialektalen Abfolge pronominaler Objekte (eine Auswertung von Wenkersatz 9). In: Elvira Glaser, Jürgen E. Schmidt \& Natascha Frey (eds.), Dynamik des Dialekts - Wandel und Variation. Aketen des 3. Kongresses der Internationalen Gesellschaft für Dialektologie des Deutschen (IGDD), 77-100. [Beiheft der Zeitschrift für Dialektologie und Linguistik 144] Stuttgart: Steiner.

Frey, Natascha \& Elvira Glaser 2007: Doubling phenomena in Swiss German dialects. In: Sjef Barbiers, Margreet van der Ham, Olaf Koeneman \& Marika Lekakou (eds.), European Dialect Syntax Project. Papers presented at the Workshop on Syntactic Doubling, Amsterdam, March 2006. Available online at http://www.meertens.knaw.nl/projecten/edisyn/Online_proceedings/Paper_Glaser-Frey.pdf.

Gilles, Peter \& Beat Siebenhaar 2010: Areal variation in segmental phonetics and phonology. In: Peter Auer \& Jürgen E. Schmidt (eds.), Language and Space, 760-786. Berlin/New York: Mouton de Gruyter.

Glaser, Elvira 2003: Schweizerdeutsche Syntax: Phänomene und Entwicklungen. In: Beat Dittli, Annelies Häcki Buhofer \& Walter Haas (eds.), Gömmer MiGro? Veränderungen und Entwicklungen im heutigen SchweizerDeutschen, 39-66. Freiburg/Schweiz: Universitätsverlag Freiburg.

Glaser, Elvira 2005: Krieg und kriegen: zur Arealität der BEKOMMEN-Periphrasen. In: Annelies Häcki Buhofer, Ulla Kleinberger Günther \& Elisabeth Piirainen (eds.), Krieg und Frieden. Auseinandersetzung und Versöhnung in Diskursen, 43-64. Tübingen: Francke Verlag.

Goebl, Hans 2010: Dialectometry and quantitative mapping. In: Alfred Lameli, Roland Kehrein \& Stefan Rabanus (eds.): Language and Space. Vol. 2: Language Mapping, 433-457. Berlin/New York: Mouton de Gruyter.

Haas, Walte 2010: A study on areal diffusion. In: Peter Auer \& Jürgen E. Schmidt (eds.), Language and Space, 649-667. Berlin/New York: Mouton de Gruyter.

Haspelmath, Martin 2008: Parametric versus functional explanations of syntactic universals. In: Theresa Biberauer \& Anders Holmberg (eds.), The Limits of Syntactic Variation, 75-107. Amsterdam: Benjamins.

Heap, David 2006: Spatial variation (geolinguistics). In: Keith Brown (ed.), Encyclopedia of Language and Linguistics, 2nd edition, 612-616. Oxford: Elsevier.

Heeringa, Wilbert \& John Nerbonne 2001: Dialect areas and dialect continua. Language Variation and Change 13: 375-400.

Heine, Bernd \& Tania Kuteva 2005: Language Contact and Grammatical Change. Cambridge: Cambridge University Press.

Holman, Eric W., Christian Schulze, Dietrich Stauffer \& Søren Wichman 2007: On the relation between structural diversity and geographical distance among languages: Observations and computer simulations. Linguistic Typology 11: 393-421.

Horvath, Barbara M. \& Ronald J. Horvath 2001: A multilocality study of a sound change in progress: The case of /1/ vocalization in New Zealand and Australian English. Language Variation and Change 13: 37-57.

Hotzenköcherle, Rudolf, Robert Schläpfer, Rudolf Trüb \& Paul Zinsli (eds.) 1975: Sprachatlas der Deutschen Schweiz. Vol. III: Formengeographie. Tübingen: Francke. 
Kelle, Bernhard 2001: Zur Typologie der Dialekte in der deutschsprachigen Schweiz: Ein dialektometrischer Versuch. Dialectologia et Geolinguistica 9: 9-34.

Knobloch, Clemens 2010: The kulturmorphologische Ansatz in dialectology and the German language space ideology. In: Peter Auer \& Jürgen E. Schmidt (eds.), Language and Space, 107-125. Berlin/New York: Mouton de Gruyter.

König, Werner (ed.) 1996-2009: Sprachatlas von Bayerisch Schwaben. Heidelberg: Winter. Kortmann, Bernd (ed.) 2004: Dialectology Meets Typology. Dialect Grammar from a CrossLinguistic Perspective. Berlin/New York: Mouton de Gruyter.

Krefeld, Thomas 2008: Räumlich fundierte Varietätenlinguistik - eine Option und ihre Geschichte. In: Gerald Bernhard and Heidi Siller-Runggaldier (eds.), Sprache im Raum - Raum in der Sprache, 91-105. (Akten der sprachwissenschaftlichen Sektion des Deutschen Italianistentages in Bochum, 23.-25. März 2006. Frankfurt et al.)

Labov, William, Sharon Ash \& Charles Boberg 2006: The Atlas of North American English. Berlin/New York: Mouton de Gruyter.

Lass, Roger 2004: South African English. In: Raymond Hickey (ed.), Legacies of Colonial English: Studies in Transported Dialects, 363-386. Cambridge: Cambridge University Press.

Löffler, Heinrich 2003: Dialektologie. Eine Einführung. Tübingen: Narr.

Longobardi, Giuseppe \& Cristina Guardiano 2009: Evidence for syntax as a signal of historical relatedness. Lingua 119: 1679-1706.

Matras, Yaron \& Jeanette Sakel (eds.) 2007: Grammatical Borrowing in Cross-linguistic Perspective. Berlin/New York: Mouton de Gruyter.

Moulton, William G. 1961: Lautwandel durch innere Kausalität: Die ostschweizerische Vokalspaltung. Zeitschrift für Mundartforschung 28: 227-251.

Nerbonne, John 2010: Measuring the Diffusion of Linguistic Change. Philosophical Transactions of the Royal Society B: Biological Sciences 365: 3821-3828.

Nerbonne, John \& Wilbert Heeringa 2007: Geographic Distributions of Linguistic Variation Reflect Dynamics of Differentiation. In: Sam Featherston \& Wolfgang Sternefeld (eds.), Roots: Linguistics in Search of its Evidential Base, 267-297. Berlin/ New York: Mouton de Gruyter.

Oesterreicher, Wulf 2001: Historizität - Sprachvariation, Sprachverschiedenheit, Sprachwandel. In: Martin Haspelmath, Ekkehard König, Wulf Oesterreicher \& Wolfgang Raible (eds.), Language Typology and Language Universals. An International Handbook, HSK 20.2, 1554-1595. Berlin/New York: Mouton de Gruyter.

Oesterreicher, Wulf 2007: Raumkonzepte in der Sprachwissenschaft: Abstraktionen Metonymien - Metaphern. Romanistisches Jahrbuch 58: 51-91.

Rumpf, Jonas, Simon Pickl, Stephan Elspaß, Werner König \& Volker Schmidt 2010: Quantification and statistical analysis of structural similarities in dialectological area-class maps. Dialectologia et Geolinguistica 18: 73-100.

Schmidt, Jürgen E. 2010: The linguistic dynamics approach. In: Peter Auer \& Jürgen E. Schmidt (eds.), Language and Space, 201-225. Berlin/New York: Mouton de Gruyter.

Seiler, Guido 2003: Präpositionale Dativmarkierung im Oberdeutschen. Stuttgart: Steiner. (Zeitschrift für Dialektologie und Linguistik, Beiheft 124).

Seiler, Guido 2004: On three types of dialect variation, and their implications for linguistic theory. Evidence from verb clusters in Swiss German dialects. In: Bernd Kortmann (ed.), Dialectology Meets Typology. Dialect Grammar from a Cross-Linguistic Perspective, 367-399. Berlin/New York: Mouton de Gruyter. 
Seiler, Guido 2005: Wie verlaufen syntaktische Isoglossen, und welche Konsequenzen sind daraus zu ziehen? In: Eckard Eggers, Jürgen Erich \& Dieter Stellmacher (eds.), Moderne Dialekte - neue Dialektologie. Akten des 1. Kongresses der Internationalen Gesellschaft für Dialektologie des Deutschen (IGDD), 313-341. Stuttgart: Steiner.

Sibler, Pius 2011: Visualisierung und geostatistische Analyse mit Daten des Syntaktischen Atlas der Deutschen Schweiz, (SADS). Masterarbeit, Geographisches Institut der Universität Zürich. http://www.geo.uzh.ch/de/lehrstuehle-und-abteilungen/geographische-informationssysteme/forschung/msc-theses.

Siebenhaar, Beat 2010: Horizontal convergence of linguistic varieties in a language space. In: Peter Auer \& Jürgen E. Schmidt (eds.), Language and Space, 241-258. Berlin/New York: Mouton de Gruyter.

Siemund, Peter \& Noemie Kintana (eds.) 2008: Language Contact and Contact Languages. Amsterdam: Benjamins.

Spruit, Marco René 2008: Quantitative perspectives on syntactic variation in Dutch dialects. Ph.D. thesis, University of Amsterdam, LOT Dissertation Series 174. Utrecht: LOT.

Spruit, Marco René, Wilbert Heeringa \& John Nerbonne 2009: Associations among linguistic levels. Lingua 119: 1624-1642.

Steiner, Janine 2006: Syntaktische Variation in der Nominalphrase - ein Fall für die Dialektgeographin oder den Soziolinguisten. In: Hubert Klausmann (ed.), Raumstrukturen im Alemannischen. Beiträge der 15. Arbeitstagung zur alemannischen Dialektologie, 109-115. Schloss Hofen, Vorarlberg. 19.-21.9.2005. Graz/Feldkirch. (Schriften der VLB, Band 15).

Szmrecsanyi, Benedikt 2012: Geography is overrated. In: Sandra Hansen, Christian Schwarz, Philipp Stoeckle \& Tobias Streck (eds.), Dialectological and Folk Dialectological Concepts of Space, 215-231. Berlin: de Gruyter. 